\title{
The Expression of Cyclophilin A in Ovarian Endometrioma: Its Correlation with Recurrence and Vascularity
}

\author{
Akin Usta, ${ }^{1}$ Gulay Turan ${ }^{2}$ and Ertan Adali ${ }^{1}$ \\ ${ }^{1}$ Department of Obstetrics and Gynecology, School of Medicine, Balikesir Univesity, Balikesir, Turkey \\ ${ }^{2}$ Laboratory of Pathology, Balikesir Ataturk State Hospital, Balikesir, Turkey
}

Endometriosis is defined as the presence of functional endometrial tissues outside of the uterine cavity. Ovarian endometrioma is the most common type of endometriosis. It is an estrogen-dependent inflammatory disease that frequently causes infertility and chronic pelvic pain. Cyclophilin A (CyPA) is secreted from various types of cells in response to inflammatory stimuli. Many previous studies have shown that the increased expression and/or heightened plasma levels of CyPA exacerbates inflammation. The aim of this study is to evaluate CyPA immunoreactivity in ovarian endometrioma cyst wall. In this cross-sectional study, CyPA immunoreactivity in endometrial tissue samples obtained from uterine cavity and in endometrioma cyst walls of 44 consecutive women with ovarian endometrioma were compared with control endometrial tissue samples obtained from uterine cavity of 40 women without endometrioma. All endometrioma samples were confirmed via histopathological examination. Finally, the relationship between CyPA immunoreactivity and the clinicopathological findings related to endometrioma were evaluated. The CyPA expression rates in glandular cells, stromal cells, and the capillary endothelium were significantly higher in endometrioma cyst walls of women with ovarian endometrioma than in the control endometrial tissue of women without endometrioma $(p=0.0002, p=0.0417$ and $p=0.0067$, respectively). The correlation analysis demonstrated that glandular CyPA expression was correlated with endometrioma recurrence $(p=0.0267)$. However, stromal and vascular endothelial CyPA expression were correlated with dysmenorrhea recurrence $(p=0.0023$ and $p=0.0003$, respectively). In conclusion, the increased expression of CyPA in ectopic endometrial tissue is associated with endometrioma recurrences and vascularity.

Keywords: cyclophilin A; dysmenorrhea; endometrioma recurrence; endometriosis; 1mmunohistochemistry Tohoku J. Exp. Med., 2017 October, 243 (2), 141-150. C 2017 Tohoku University Medical Press

\section{Introduction}

Endometriosis is defined as presence and growth of endometrial-like tissue outside of the uterine cavity (Missmer et al. 2004). It is one of the most prevalent disease that affects $10 \%$ of reproductive age women (Yamamoto et al. 2017). Although not associated with high mortality, this disorder can significantly contributes to a decrease in the quality of life (Soliman et al. 2017). Ovarian endometrioma is the most common type of endometriosis and frequently causes chronic pelvic pain (CPP) and infertility (Busacca and Vignali 2003).

Currently, many surgical techniques, medical drugs, and combinations of the two can be used in the treatment of endometriosis (Singh and Suen 2017). However, a cure for endometriosis is not possible, and the recurrence of this disease and its related symptoms is commonplace. Thus, it is important to understand the underlying molecular and cel- lular mechanisms of this disease (Bischoff and Simpson 2004).

Endometriosis is characterized by a chronic inflammatory reaction in the pelvis; additionally, various biomarker alterations may occur in women with endometriosis, including increased levels of reactive oxygen species (ROS), proteolitic enzyme and inflammatory molecules in endometriotic foci, endometrioma fluid and circulation (Yamaguchi et al. 2008). The overproduction of ROS causes harmful effects on those cells that exceed the cellular antioxidant defense capacity for the removal of these toxic substances, thus resulting in oxidative stress. ROS-induced oxidative stress alters cellular function by regulating the gene expression and protein activity of pro-inflammatory cytokines, adhesion molecules, and various growth and angiogenic factors as well as by affecting the normal action of important signaling pathways, such as the mitogen-activated protein kinase (MAPK) pathways, the AP-1 transcription fac-

Received September 8, 2017; revised and accepted October 13, 2017. Published online October 28, 2017; doi: 10.1620/tjem.243.141.

Correspondence: Akin Usta, Asst. Prof., Department of Obstetrics and Gynecology, Balıkesir University Faculty of Medicine, Cagis

Yerleskesi, Bigadic yolu 17. km 10145 Balikesir, TURKIYE.

e-mail: drakinusta@gmail.com 
tor, the NF-kB pathway and hypoxia-inducible transcription factors (Wu 2006; Defrère et al. 2011; Sanchez et al. 2014). Many previous studies have clearly indicated that the presence of oxidative stress in endometrioma and surrounding ovarian tissues (Matsuzaki and Schubert 2010). Oxidative stress can lead to chronic inflammation, which can mediate the formation of many chronic illnesses such as cancer, diabetes and various cardiovascular, neurological, and pulmonary diseases (Reuter et al. 2010).

Cyclophilin A (CyPA), an $18 \mathrm{kDa}$ weight intracellular protein, is a member of the immunophilin family. It is known as an inflammatory mediator that is secreted from various types of cells in response to inflammatory stimuli such as hypoxia, oxidative stres, and infection. Previous reports have shown that the expression and/or circulating levels of CyPA are higher in the presence of several disorders such as diabetes mellitus, asthma, rheumatoid arthritis, cardiovascular disease, and cancer, which causes inflammatory conditions in the body (Billich et al. 1997; Yang et al. 2007; Li et al. 2008; Nigro et al. 2011; Stemmy et al. 2011; Satoh et al. 2013; Ramachandran et al. 2014). During the inflammation process, the increased secretion of CyPA stimulates the production of cytokines as well as the migration of inflammatory cells, including monocytes/macrophages and neutrophils (Yang et al. 2008; Tian-tian et al. 2013). Additionally, CyPA with its receptor CD147 (is also called Basigin and EMMPRIN) interaction significantly enhances tissue destruction and cell invasion via the elevated secretion of MMPs (Yang et al. 2008; Wang et al. 2010; Tian-tian et al. 2013).

However, many previous studies have demonstrated that CyPA knockdown serves to protect individuals from the detrimental effects of inflammation associated with many diseases, including atherosclerosis (Satoh et al. 2011), ischemia/reperfusion injury (Seizer et al. 2011), and tumor growth in vivo ( $\mathrm{Li}$ et al. 2008).

A recent study conducted by Li et al. (2008) has shown that CyPA is present in normal endometrial tissues and that CyPA expression is higher in the pathological endometrial tissues of women with endometrial hyperplasia and endometrial cancer, which cause an inflammatory condition to occur in the endometrium. Moreover, the authors found that an overeexpression of CyPA is correlated with poor differentiation and a prognosis of endometrial cancer. In the same study, the suppression of CyPA in vivo was shown to result in decreased tumor growth accompanied by the inhibition of cell proliferation and the induction of apoptosis. Finally, the authors concluded that CyPA is a promising novel prognostic factor and possibly also a potential therapeutic target in the treatment of endometrial carcinoma.

Based on the above considerations, the purpose of this study was to evaluate the alteration of CyPA expression and subcellular localization in the endometrial tissue (eutopic endometrium) samples and in the endometrioma cyst wall (ectopic endometrium) tissue samples of women with endometrioma. We also evaluated possible correlations between
CyPA expression in the ectopic endometrium and clinicopathological variables of women with endometrioma.

\section{Materials and Methods}

\section{Patients}

This cross-sectional study was conducted in Balikesir University, School of Medicine, Training and Research Hospital between January 2015 and July 2016. The investigation protocol was approved by the institutional Ethical Committee of the Balikesir University, School of Medicine. All subjects gave informed consent before participation. The protocols of the study were in accordance with the Helsinki Committee requirements.

Fourty-four consecutive women (35 sexually active and 9 virgin) who were undergoing laparoscopic endometrioma excision were included in this study. Endometrial tissue samples (eutopic endometrium) were obtained from uterine cavity of 35 sexually active women and endometrioma cyst wall tissues (ectopic endometrium) were obtained from cyst walls of all 44 women with ovarian endometrioma during endometrioma surgery.

For the control group, endometrial tissue samples (control endometrium) were obtained from uterine cavity of 40 women who were undergoing laparoscopic surgery for benign indication such as tubal sterilization, myoma uteri, and serous and mucinous cystadenoma of the ovary.

The demographic characteristics of the patients were recorded prior the surgery. Laparoscopic endometrioma excisions were performed using the stripping method on all patients with endometrioma. All procedures were performed under general anesthesia and all operations were performed with laparoscopy. No intraoperative complication was occurred. All patients were discharged home within 48 hours after the surgery, without any major post-operative complication. All patients were followed at least one year postoperatively.

Endometrioma were diagnosed with ultrasonography and later histopathologically confirmed. Women who had pelvic infections, pelvic malignancy, serious systemic diseases, advanced pelvic adhesion, pelvic radiation exposure, deep infiltrative endometriosis (DIE) and hormone replacement therapy (HRT) before 3 month the operation were excluded from the study.

Recurrence of endometrioma: During the followed period, presence of ovarian cysts of $>2 \mathrm{~cm}$ diameter, along with characteristic echoes as detected by transvaginal ultrasonography for two consecutive menstruation (Exacoustos et al. 2006) or the presence of de novo ovarian endometrioma as confirmed by histology following a second surgery was defined as endometrioma recurrence. According to these observations, women with endometrioma were divided into two groups as endometrioma recurrence $(n=9)$ and non-recurrence $(n=$ $35)$.

Recurrence of dysmenorrhea: Recurrence of dysmenorrhea was defined as a recurrence or persistence of pain symptoms requiring medical intervention with menstration after the surgery. Presence of dysmenorrhea was questioned verbally at preoperative and postoperative evaluation (routine practice at our clinic).

Tissue specimens preparation and examination: Endometrial tissue specimens; All pathological specimens of the endometrial tissues of 35 women with endometrioma and of the 40 control women were fixed in formalin and subsequently embedded in paraffin. They were then cut into $4-\mu \mathrm{m}$ thick sections and stained with hematoxylin and eosin.

Endometrioma cyst wall tissue specimens: The endometrioma 
cyst wall tissue samples of 44 women with endometrioma were obtained during the surgery. For the purpose of standardizing the tissue sampling procedure, biopsies of the endometrioma cyst walls were obtained from the site closest to the ovarian hilus following the removal of the endometrioma. Formalin-fixed specimens were embedded in paraffin and cut into $4-\mu \mathrm{m}$ thick sections and stained with hematoxylin and eosin.

\section{Immunohistochemistry}

Immunohistochemical staining for CyPA was performed on both the endometrial tissue samples and the endometrioma cyst wall tissue samples. During the immunohistochemistry procedure: all biopsy specimens were fixed in $10 \%$ neutral formalin and then subsequently embedded in paraffin. Four $-\mu \mathrm{m}$ sections were mounted on to glass slides and allowed to dry at $37^{\circ} \mathrm{C}$ for $12 \mathrm{~h}$. Each sample was passed through xylene and ethanol series for removing paraffins. Next, to prevent endogenous peroxidase activities, samples were incubated with $1 \% \mathrm{H}_{2} \mathrm{O}_{2}$. Each sample was washed with $0.1 \%$ triton$\mathrm{x}-100$ phosphate buffered saline (PBS) and transferred to citrate buffer solution $(\mathrm{pH} 6)$ to provide antigen retrieval. After, specimens were washed with PBS again and put into an immunohistochemistry container. Then, primary antibodies for CyPA was added and refrigerated at $4{ }^{\circ} \mathrm{C}$ for $12 \mathrm{~h}$. After, samples were washed with PBS and incubated with streptavidin peroxidase for $30 \mathrm{~min}$. Next, specimens were then rinsed again with PBS and incubated with chromogen aminoethylcarbazole substrate kit (AEC kit; Zymed Laboratories). After this procedure, the slides were stained with hematoxylin for background staining and covered with mounting medium solution (Zymed 00-8030).

Immunohistochemistry analysis was performed using the super vision assay kit (SV0002-1, Boster, Pleasanton, CA, USA) in the Department of Pathology by a histopathologist. The primary antibodies used in this study was human monoclonal antibody against cyclophilin A, dilution 1:100; (PA/1447, Boster, Pleasanton, CA, USA).

Evaluation of all tissue samples: During the evaluation, an experienced histopathologist (G.T.) was blinded to the clinical variables. All participants endometriomas underwent gross and histologic examinations. During the gross examinations, the size of the endometrioma, its bilaterality and the presence of peritoneal endometriosis lesions were recorded.

During the histologic examinations, vascularization of the cyst wall tissue was evaluated per random selected fields of the tissue specimens via light microscopy under $\times 20$ magnification. The area surrounding the blood vessels was quantified using computer software. During the procedure, the vascular wall was manually outlined with the aid of the image analysis system per random selected fields of the cyst wall tissues. The fraction of blood vessels was brought back to the total area (on the selected field) and assessed using a computerized analysis system (mean determination from the selected field).

In all patients with endometrioma, the eutopic and ectopic endometrial tissue samples showed strong immunoreactivity for CyPA. CyPA expression was predominantly localized in intracytoplasmic glandular cells, in stromal cells and in the capillary endothelium. However, there were differences with regard to staining intensity between in endometrial glandular cells, endometrial stromal cells, and the capillary endothelium of the same endometrial tissue samples. Therefore, we have separately scored CyPA expression in different cells. Analyzed fields selected randomly from ten slides using a biomicroscope (Olympus BX48, Tokyo, Japan) and an image analysis system (Nis Elements Advantages Research Microscope Imaging Software, Nikon Enstruments Europe BV, Amsterdam, Netherlands). The image analysis system used consisted of a PC with hardware and software for image acquisition and analysis, a spot insight camera, and an optical microscope. The method requires preliminary software procedures involving spatial calibration (on a micron scale) and setting of color segmentation for quantitative color analysis. Browncolor staining intensity in the cytoplasm of the columnar cells, stromal cells and capillary endothelium revealed the presence of CyPA expression. The positivity ratio was evaluated; the number of pixels reflects the expression level of the detected antigen and can also be expressed as percentage of the entire image pixel amount. $<80$ pixels reflects: weak $(1+), 80-200$ pixels reflects: moderate $(2+)$ or $>200$ pixels reflects: strong (3+) (see Fig. 2A, B and Fig. 3A, B, C).

For statistical analysis, comparisons of metric or categorical variables between patients and controls were done by indepentent $t$ test or Mann-Whitney test. Qualitative data are expressed in percentage (\%) and quantitative data are expressed as the means \pm standard deviation (SD). $\mathrm{p}$ values of $<0.05$ were considered to be statistically significant. MedCalc Statistical Software Programme Version 17.2 (Ostend, Belgium) was used.

\section{Results}

In this cross-sectional study, CyPA immunoreactivity in the endometrial tissue samples (eutopic endometrium, $\mathrm{n}$ $=35$ ) and in the endometrioma cyst wall tissue samples (ectopic endometrium, $n=44$ ) of women with endometrioma were compared with the endometrial tissue samples of age-matched women without endometrioma (control endometrium, $\mathrm{n}=40$ ).

The morphological analysis of tissue samples using light microscopy showed that the endometrioma cyst walls were mainly composed of fibrous connective tissue, blood vessels, and an inner cyst wall of endometrioma covered by endometriotic tissue (ectopic endometrium), which included a lining of columnar epithelium, the endometriotic gland, endometriotic stroma, capillary vessels, and hemosiderinladen macrophages (Fig. 1).

\section{Overexpression of Cyclophilin A in the eutopic and ectopic} endometrial tissues of women with endometrioma

Importantly, CyPA expression in women with endometrioma was significantly higher than that it was in women without endometrioma (Fig. 2A, B). The statistical analysis revealed that CyPA expression in glandular cells, stromal cells, and the capillary endothelium was significantly higher in the eutopic and ectopic endometrial tissues of women with endometrioma than in the control endometrial tissues of women without endometrioma $(p=0.0002, p$ $=0.0417$ and $\mathrm{p}=0.0067$, respectively). Our subgroup analysis showed that glandular CyPA expression in ectopic and eutopic endometrial tissue were significantly higher than control endometrial tissue $(p<0.0001$ and $p=0.0024$, respectively). Stromal CyPA expression in ectopic and eutopic endometrial tissue were significantly higher than 


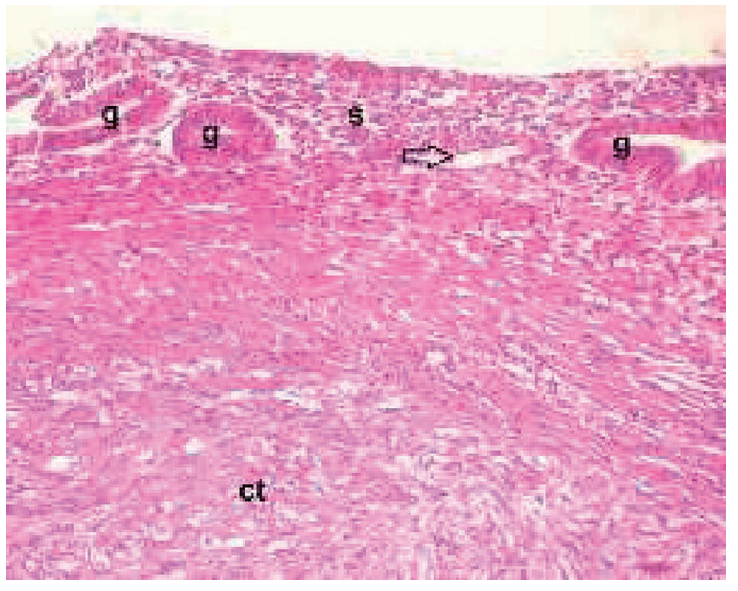

Fig. 1. Hematoxylin-Eosin staining in endometrioma cyst wall $(\times 200)$

The endometrioma cyst walls were mainly composed of fibrous connective tissue, blood vessels, and ectopic endometrial tissue which included a lining of columnar epithelium, the endometriotic gland, endometriotic stroma, blood vessels, and hemosiderin-laden macrophages. $\mathrm{g}$, endometriotic gland; s, endometriotic stroma; ct, fibrous connective tissue; arrow, blood vessels. control endometrial tissue $(p=0.0134$ and $p=0.0279$, respectively). Vascular endothelial CyPA expression in ectopic and eutopic endometrial tissue was significantly higher than control endometrial tissues $(p=0.0019$ and $p=0.0206$, respectively). However, there were no differences in glandular cells, stromal cells and vascular endothelial expression of CyPA between between eutopic and ectopic endometrial tissues of women with endometrioma $(\mathrm{p}=0.3782$, $\mathrm{p}$ $=0.6832, \mathrm{p}=0.6281$, respectively). The expression of CyPA in all tissue samples is shown in Table 1.

Comparable analysis of clinicopathological variables in women with and without endometrioma recurrence

Clinically, we observed that $18.2 \%$ of women had endometrioma in both ovaries, and $22.7 \%$ of patients had peritoneal endometriotic lesions. We also found that in our study population, endometrioma recurrence and dysmenorrhea recurrence were $20.5 \%$ and $52.3 \%$, respectively, one year after surgery.

The clinical and histopathological variables in women with endometrioma were compared between groups. The nine women in the recurrence group had a median age of 31 (range 23-41 years) years and the 35 women in the non-
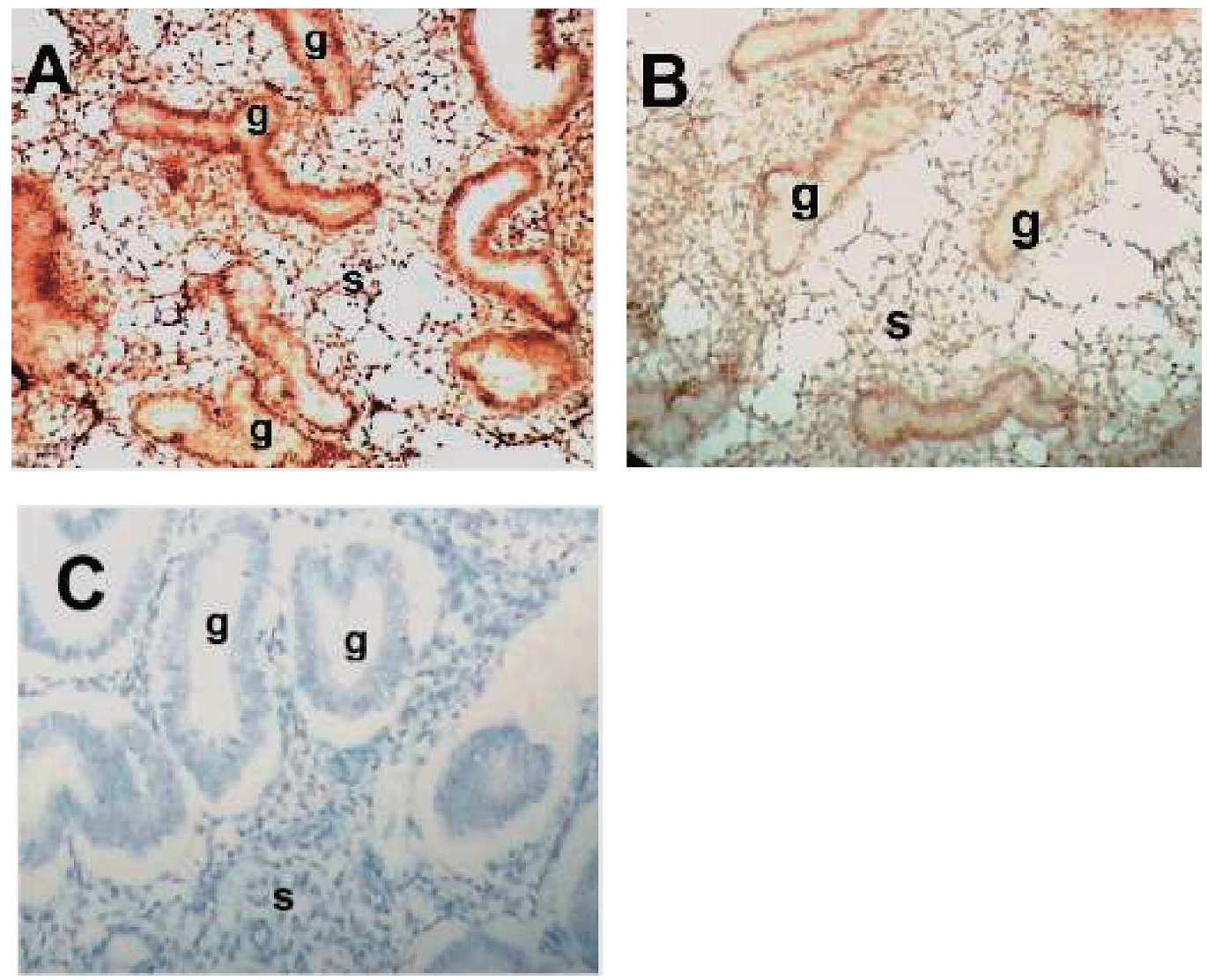

Fig. 2. Different expression of CyPA in endometrial tissues by immunohistochemistry $(\times 200)$.

(A) CyPA expression in a woman with endometrioma revealing strong cytoplasmic staining in columnar and stromal cells (dark brown, score 3). (B) Weak expression of CyPA in a woman without endometrioma (light brown staining, score 1). (C) Negative control: the endometrial tissue of the uterine cavity, obtained from a woman without ovarian endometrioma.

$\mathrm{g}$, endometrial gland; s, endometrial stroma. 
Table 1. The expression of CyPA in endometrial tissues of women with and without endometrioma.

\begin{tabular}{|c|c|c|c|c|c|c|c|c|c|c|}
\hline & \multicolumn{6}{|c|}{ Endometrioma } & \multirow{2}{*}{\multicolumn{3}{|c|}{$\begin{array}{c}\text { Non-Endometrioma } \\
\text { Control endometrial tissue } \\
(\mathrm{n}=40)\end{array}$}} & \multirow[b]{3}{*}{ p value* } \\
\hline \multirow[t]{2}{*}{$\begin{array}{l}\text { The expression } \\
\text { of CyPA }\end{array}$} & \multicolumn{3}{|c|}{$\begin{array}{l}\text { Ectopic endometrial tissue } \\
\qquad(n=44)\end{array}$} & \multicolumn{3}{|c|}{$\begin{array}{l}\text { Eutopic endometrial tissue } \\
\qquad(n=35)\end{array}$} & & & & \\
\hline & $1+$ & $2+$ & $3+$ & $1+$ & $2+$ & $3+$ & $1+$ & $2+$ & $3+$ & \\
\hline $\begin{array}{c}\text { Glandular cells, } \\
n(\%)\end{array}$ & $\begin{array}{l}10 \\
(22.7 \%)\end{array}$ & $\begin{array}{l}13 \\
(29.5 \%)\end{array}$ & $\begin{array}{l}21 \\
(47.7 \%)\end{array}$ & $\begin{array}{l}11 \\
(31.4 \%)\end{array}$ & $\begin{array}{l}10 \\
(28.6 \%)\end{array}$ & $\begin{array}{l}14 \\
(40 \%)\end{array}$ & $\begin{array}{l}27 \\
(67.5 \%)\end{array}$ & $\begin{array}{l}9 \\
(22.5 \%)\end{array}$ & $\begin{array}{l}4 \\
(10 \%)\end{array}$ & 0.0002 \\
\hline $\begin{array}{l}\text { Stromal cells, } \\
n(\%)\end{array}$ & $\begin{array}{l}17 \\
(38.6 \%)\end{array}$ & $\begin{array}{l}11 \\
(25 \%)\end{array}$ & $\begin{array}{l}16 \\
(36.3 \%)\end{array}$ & $\begin{array}{l}12 \\
(34.3 \%)\end{array}$ & $\begin{array}{l}9 \\
(25.7 \%)\end{array}$ & $\begin{array}{l}14 \\
(40 \%)\end{array}$ & $\begin{array}{l}25 \\
(62.5 \%)\end{array}$ & $\begin{array}{l}10 \\
(25 \%)\end{array}$ & $\begin{array}{l}5 \\
(12.5 \%)\end{array}$ & 0.0417 \\
\hline $\begin{array}{c}\text { Vascular } \\
\text { endothelium, } n \\
(\%)\end{array}$ & $\begin{array}{l}8 \\
(18.1 \%)\end{array}$ & $\begin{array}{l}22 \\
(50 \%)\end{array}$ & $\begin{array}{l}14 \\
(31.8 \%)\end{array}$ & $\begin{array}{l}9 \\
(25.7 \%)\end{array}$ & $\begin{array}{l}15 \\
(42.9 \%)\end{array}$ & $\begin{array}{l}11 \\
(31.4 \%)\end{array}$ & $\begin{array}{l}21 \\
(52.5 \%)\end{array}$ & $\begin{array}{l}15 \\
(37.5 \%)\end{array}$ & $\begin{array}{l}4 \\
(10 \%)\end{array}$ & 0.0067 \\
\hline
\end{tabular}

*Chi-squared test.

The expression of CyPA in glandular cells, stromal cells, and the capillary endothelium was significantly higher in the eutopic and ectopic endometrial tissues of women with endometrioma than in the control endometrial tissues of women without endometrioma $(p=$ $0.0002, p=0.0417$ and $\mathrm{p}=0.0067$, respectively). The subgroup analysis showed that glandular CyPA expression in ectopic and eutopic endometrial tissue was significantly higher than control endometrial tissues $(\mathrm{p}<0.0001$ and $\mathrm{p}=0.0024$, respectively). Stromal CyPA expression in ectopic and eutopic endometrial tissue was significantly higher than control endometrial tissues $(p=0.0134$ and $p=$ 0.0279 , respectively). Vasculary endothelial CyPA expression in ectopic and eutopic endometrial tissue was significantly higher than control endometrial tissue $(p=0.0019$ and $p=0.0206$, respectively). However, there were no differences in glandular cells, stromal cells and vascular endothelial expression of CyPA between between eutopic and ectopic endometrial tissues of women with endometrioma $(\mathrm{p}=0.3782, \mathrm{p}=0.6832, \mathrm{p}=0.6281$, respectively).

Table 2. Demographic characteristics of women with ovarian endometrioma in the recurrence and non-recurrence groups.

\begin{tabular}{|c|c|c|c|}
\hline & Recurrence $(n=9)$ & Non-recurrence $(n=35)$ & $p$ value \\
\hline Mean age, year & $31(23-41)$ & $30(21-39)$ & $0.4396^{a}$ \\
\hline $\begin{array}{l}\text { Parity, n (\%) } \\
\text { Nulliparity } \\
\text { Multiparity }\end{array}$ & $\begin{array}{l}4(44.4 \%) \\
5(55.6 \%) \\
\end{array}$ & $\begin{array}{l}24(68.6 \%) \\
11(31.4 \%) \\
\end{array}$ & $0.4677^{b}$ \\
\hline $\begin{array}{l}\text { Previous abdominal surgery, } \mathrm{n}(\%) \\
\text { No } \\
\text { Yes }\end{array}$ & $\begin{array}{l}7(77.8 \%) \\
2(22.2 \%) \\
\end{array}$ & $\begin{array}{l}32(91.4 \%) \\
3(8.6 \%)\end{array}$ & $0.2552^{b}$ \\
\hline $\begin{array}{l}\text { Sexual Behaviour, } \mathrm{n}(\%) \\
\text { Sexually active, } \\
\text { Virgin }\end{array}$ & $\begin{array}{l}8(88.9 \%) \\
1(11.1 \%)\end{array}$ & $\begin{array}{l}27(77.1 \%) \\
8(22.9 \%)\end{array}$ & $0.4412^{b}$ \\
\hline Serum level of CA125, mean (U/mL) & $65(33-161.6)$ & $87(49-112.4)$ & $0.1625^{\mathrm{a}}$ \\
\hline Endometrioma cyst diameter, mean (mm) & $51(35-121)$ & $63(49-98)$ & $0.0808^{\mathrm{a}}$ \\
\hline $\begin{array}{l}\text { Bilaterality of endometrioma, } \mathrm{n}(\%) \\
\text { Unilateral } \\
\text { Bilateral }\end{array}$ & $\begin{array}{l}7(77.8 \%) \\
2(22.2 \%) \\
\end{array}$ & $\begin{array}{l}29(82.9 \%) \\
6(17.1 \%)\end{array}$ & $0.7276^{b}$ \\
\hline $\begin{array}{l}\text { Presence of peritoneal endometriosis } \\
\text { lesions, } \mathrm{n}(\%) \\
\text { No } \\
\text { Yes }\end{array}$ & $\begin{array}{l}6(66.7 \%) \\
3(33.3 \%)\end{array}$ & $\begin{array}{l}28(80 \%) \\
7(20 \%)\end{array}$ & $0.4000^{b}$ \\
\hline $\begin{array}{l}\text { Dysmenorrhea recurrence, } \mathrm{n}(\%) \\
\text { No } \\
\text { Yes }\end{array}$ & $\begin{array}{l}4(44.4 \%) \\
5(55.6 \%)\end{array}$ & $\begin{array}{l}23(65.7 \%) \\
12(34.3 \%)\end{array}$ & $0.2479^{b}$ \\
\hline Vascularity median, (min-max) & $27.3(13.1-41.9)$ & $18.1(6.2-38.1)$ & $0.0081^{\mathrm{a}}$ \\
\hline $\begin{array}{l}\text { Ectopic CyPA immunoreactivity } \\
\text { Score, mean } \pm \text { SD } \\
\text { Glandular cells } \\
\text { Stromal cells } \\
\text { Vascular endothelium }\end{array}$ & $\begin{array}{l}2.78 \pm 0.66 \\
2.11 \pm 0.78 \\
2.22 \pm 0.44\end{array}$ & $\begin{array}{l}2.11 \pm 0.79 \\
1.94 \pm 0.82 \\
2.11 \pm 0.76\end{array}$ & $\begin{array}{l}\mathbf{0 . 0 2 6 7 ^ { a }} \\
0.6130^{a} \\
0.6857^{a}\end{array}$ \\
\hline
\end{tabular}

a, Mann-Whitney test; b, Chi-squared test.

recurrence group had a median age of 30 years (range 21-39 years). There were no differences in age or parity between the groups ( $\mathrm{p}=0.4396$ and $\mathrm{p}=0.4677$, respectively). The characteristics of these participants are summarized in Table 2.

Importantly, women with endometrioma recurrence 

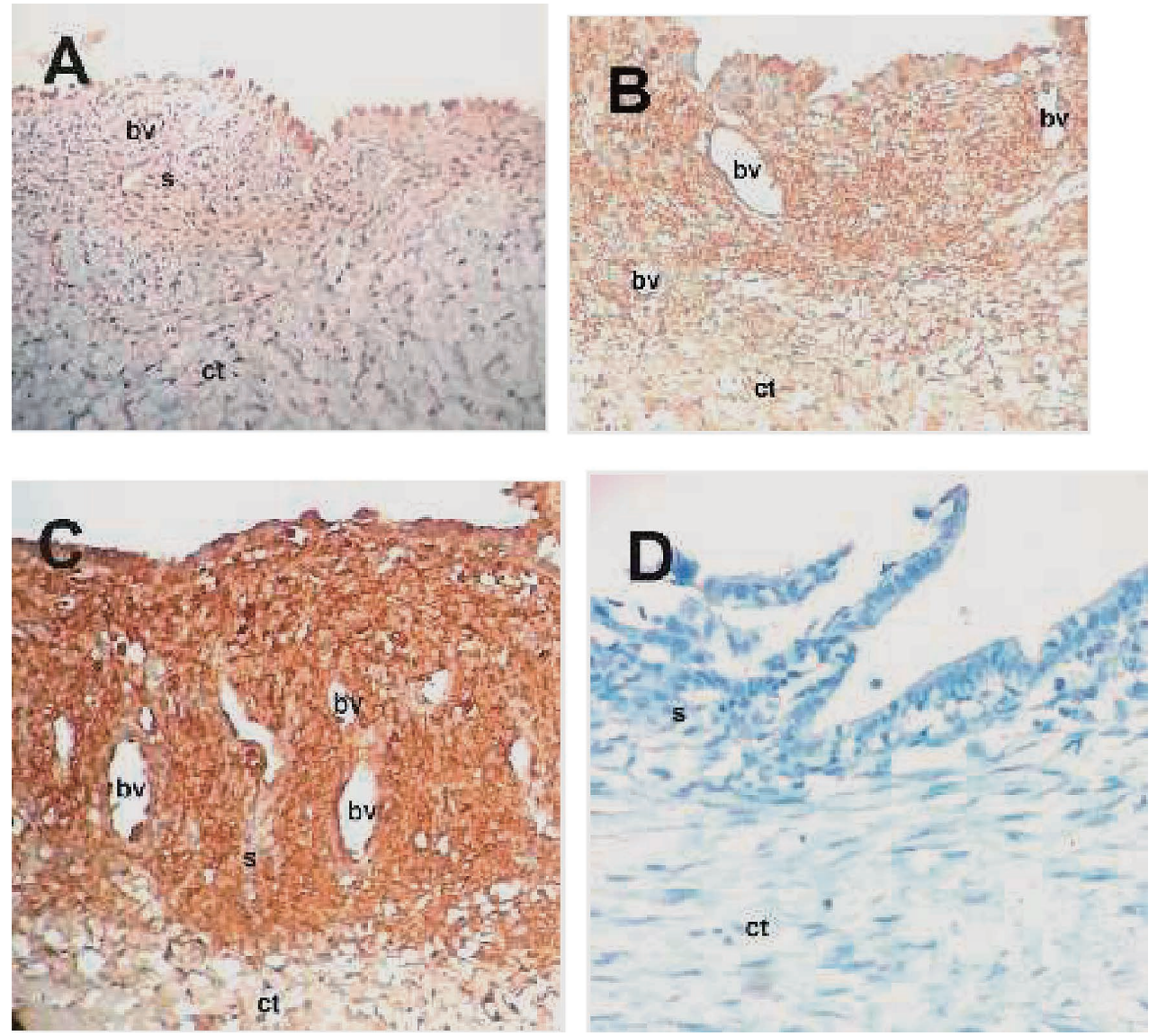

Fig. 3. CyPA expression in endometrioma cyst wall tissue by immunohistochemistry $(\times 200)$.

(A) CyPA expression in a woman without endometrioma and dysmenorrhea recurrence revealing light staining in columnar epithelium, stroma and endothelial cells (light brown, score 1). (B) CyPA expression in a woman with dysmenorrhea recurrence revealing staining in some columnar cells and stromal cells (light brown, score 2), whereas strong staining in endothelial cells (dark brown, score 3), however light staining in some columnar epithelium (light brown, score 1). (C) CyPA expression in a woman with endometrioma recurrence revealing strong staining in columnar epithelium, stroma and endothelial cells (dark brown, score 3). (D) Negative control: the endometriotic tissue of the endometrioma cyst wall, obtained from a woman with ovarian endometrioma.

$\mathrm{g}$, endometriotic gland; s, endometriotic stroma; bv, blood vessels; ct, fibrous connective tissue.

had a significantly higher CyPA expression in their glandular cells (Fig. 3A, B, C) than did women without endometrioma recurrence. Additionally, the statistical analysis revealed that glandular CyPA expression in the recurrence group was significantly higher than in the non-recurrence group $(p=0.0267)$. However, CyPA expression in the stromal and vascular endothelial cells was similar between the groups ( $p=0.6130$ and $p=0.6857$, respectively) (Table 2 ).

Moreover, the vascularization of ectopic endometrial tissues was compared between both groups per random selected fields of the tissue speciments via light microscopy. The fractional area of blood vessels in the ectopic endometrial tissues of women with endometrioma recurrence was compared with that of non-recurrence patients. Notably, we found that women with endometrioma recurrence had significantly increased fractional areas of blood vessels than did women without endometrioma recurrence. The fractional areas of blood vessels were then measured with the medians of $27.3 \%$ and $18.1 \%$ in the recurrence and non- recurrence groups, respectively $(\mathrm{p}=0.0081)$.

Correlation analysis between CyPA expression and clinicopathological variables of women with endometrioma

As shown in Table 3, glandular CyPA expression was correlated with various clinical parameters, including the bilaterality of endometrioma, the maximal diameter of cyst walls, and endometrioma recurrence $(\mathrm{p}=0.0373, \mathrm{p}=$ 0.0141 and $\mathrm{p}=0.0267$, respectively). However, stromal and vascular endothelial CyPA expression was correlated only with dysmenorrhea recurrence $(\mathrm{p}=0.0023$ and $\mathrm{p}=$ 0.0003 , respectively). CyPA expression in glandular cells, stromal cells and the capillary endothelium was correlated with the vascularity of endometrioma $(p=0.0149, p=$ 0.0348 and $p=0.0165$, respectively). There were no correlations between CyPA expression and patient age, parity, or serum levels of CA125, a tumor marker. 
Table 3. Correlation analysis between glandular, stromal and capillary endothelial CyPA expression and clinicopathological variables.

\begin{tabular}{|c|c|c|c|}
\hline Variables & $\begin{array}{l}\text { Glandular } \\
\text { CyPA }\end{array}$ & $\begin{array}{l}\text { Stromal } \\
\text { CyPA }\end{array}$ & $\begin{array}{c}\text { Capillary endothelial } \\
\text { CyPA }\end{array}$ \\
\hline Age & $\begin{array}{c}-0.2030 \\
p=0.1864\end{array}$ & $\begin{array}{l}-0.06312 \\
p=0.6840\end{array}$ & $\begin{array}{c}-0.2205 \\
p=0.1503\end{array}$ \\
\hline Parity & $\begin{array}{c}0.01496 \\
p=0.9232\end{array}$ & $\begin{array}{l}-0.09188 \\
p=0.5530\end{array}$ & $\begin{array}{c}-0.1413 \\
p=0.3601\end{array}$ \\
\hline CA125 level & $\begin{array}{l}-0.009213 \\
p=0.9527\end{array}$ & $\begin{array}{l}-0.08332 \\
p=0.5908\end{array}$ & $\begin{array}{l}0.005286 \\
p=0.9728\end{array}$ \\
\hline Endometrioma diameter & $\begin{array}{c}0.3150 \\
p=0.0373\end{array}$ & $\begin{array}{c}0.2218 \\
p=0.1479\end{array}$ & $\begin{array}{c}0.1747 \\
p=0.2566\end{array}$ \\
\hline Bilaterality of endometrioma & $\begin{array}{c}0.3677 \\
p=0.0141\end{array}$ & $\begin{array}{c}0.2166 \\
p=0.1579\end{array}$ & $\begin{array}{c}0.2471 \\
p=0.1059\end{array}$ \\
\hline Presence of peritoneal endometriosis lesions & $\begin{array}{c}0.1015 \\
p=0.5120\end{array}$ & $\begin{array}{c}0.01424 \\
p=0.9269\end{array}$ & $\begin{array}{c}-0.1066 \\
p=0.4911\end{array}$ \\
\hline Endometrioma recurrence & $\begin{array}{c}0.3340 \\
p=0.0267\end{array}$ & $\begin{array}{c}0.07839 \\
p=0.6130\end{array}$ & $\begin{array}{c}0.07140 \\
p=0.6857\end{array}$ \\
\hline Dysmenorrhea recurrence & $\begin{array}{c}0.2413 \\
p=0.1145\end{array}$ & $\begin{array}{c}0.4479 \\
p=0.0023\end{array}$ & $\begin{array}{c}0.5157 \\
p=0.0003\end{array}$ \\
\hline Vascularity & $\begin{array}{c}0.3648 \\
p=0.0149\end{array}$ & $\begin{array}{c}0.3189 \\
p=0.0348\end{array}$ & $\begin{array}{c}0.3597 \\
p=0.0165\end{array}$ \\
\hline
\end{tabular}

*Spearman's rank correlation.

\section{Discussion}

In the present study, we investigated the expression of CyPA in the eutopic and ectopic endometrial tissues of women with endometrioma and compared them with the normal endometrial tissues from women in the control group. According to our results, women with endometrioma had significantly higher levels of CyPA expression in glandular cells, stromal cells, and the capillary endothelium of both eutopic and ectopic endometrial tissues as compared to normal endometrial tissues from age-matched controls.

Moreover, CyPA expression in the glandular cells was significantly correlated with the presence of endometrioma recurrence, the bilaterality of endometrioma, and endometrioma cyst diameter. Additionally, CyPA expression in the stromal cells and capillary endothelium was correlated with pain recurrence.

Furthermore, we evaluated the vascularity of the ectopic endometrial tissues of women with and without endometrioma recurrence. We found that there was an increase in the vascularization of ectopic endometrium in women with endometrioma recurrence as compared to women without recurrence. Moreover, CyPA expression in glandular cells, stromal cells, and the capillary endothelium was correlated with the vascularity of the endometrioma. To our knowledge, this is the first study to examine CyPA expression in the eutopic and ectopic endometrial tissues of women with endometrioma.

Endometriosis is a chronic inflammatory disease that involves multifactorial etiology and that is characterized by the presence and growth of functional endometrial tissues in abnormal sites other than the endometrium (Ho et al. 1997; Missmer et al. 2004). There are various biomarker alterations associated with inflammation in the eutopic and ectopic endometrial tissues of women with endometriosis (Grandi et al. 2017). However, the molecular mechanisms that play a role in the pathogenesis of endometriosis are still under investigation.

CyPA is known as an inflammatory mediator that is secreted from various types of cells in response to inflammatory stimuli, such as hypoxia, oxidative stress, and infection. Many of the previous reports have shown that the expression and/or circulating levels of CyPA are higher in the presence of disorders related to inflammatory conditions (Billich et al. 1997; Yang et al. 2007; Li et al. 2008; Nigro et al. 2011; Stemmy et al. 2011; Satoh et al. 2013; Ramachandran et al. 2014). For example, Satoh et al. (2013) reported that CyPA expression is significantly higher in the atherosclerotic plaque of arterial walls in patients with atherosclerosis. Additionally, Stemmy et al. (2011) revealed a higher concentrations of extracellular CyPA in the chronic phase of asthma using a murine model. Billich et al. (1997) found that CyPA levels were increased in the synovial fluids of patients with rheumatoid arthritis (RA). Ramachandra et al. (2014) reported that plasma CyPA levels were significantly higher in patients with type 2 diabetes mellitus than in the non-diabetic population. Yang et al. (2007) demonstrated that CyPA expression is significantly higher in patients with small lung cancer. A recent study conducted by $\mathrm{Li}$ et al. (2008) indicated an overexpression of CyPA in the endometrial tissues of women with endometrial cancer. In the current study, we found higher levels of CyPA expression in both the eutopic and ectopic endometrial tissues of women with endometrioma as compared to control subjects. In light of these reports, our findings indicate that overexpression of CyPA in the endometriotic cells 
may reflect a response to oxidative stress.

However, previous studies have shown that under inflammatory conditions, secreted CyPA acts as an autocrine and paracrine factor that exacerbates oxidative stress and inflammation (Satoh et al. 2013). It is known that endometriosis causes a local inflammatory response (Yamaguchi et al. 2008). Even so, the fact that CyPA can be secreted from the cell suggests that it can be detected in circulation. However, whether or not elevated plasma concentrations of CyPA are accompanied by endometriosis is a question that remains open and requires further study.

Many of previous studies have clearly indicated that an overexpression of CyPA is correlated with poor outcomes in patients with inflammatory diseases (Stemmy et al. 2011). During the inflammation process, CyPA exacerbates oxidative stress and inflammation (Satoh et al. 2011). Clinically, we observed that in our study population conservative surgery for endometrioma was associated with a $20.5 \%$ likelihood of endometrioma recurrence and a $52.3 \%$ likelihood of dysmenorrhea recurrence one year after the surgery for endometrioma; our current results are therefore in line with those of previous studies (Vercellini et al. 2006). Interestingly, we found that an overexpression of CyPA in glandular cells was associated with endometrioma recurrence, whereas stromal and vascular endothelial CyPA expression were both correlated with dysmenorrhea recurrence. The expression pattern of CyPA in ectopic endometrial tissue suggests that it may play a role in the survival of endometrioma and in the pathological mechanism of endometrioma-associated pain.

Angiogenesis is known to play a major role in the growth and survival of endometriosis (Inan et al. 2003; Di Carlo et al. 2009; Laschke et al. 2011; Li et al. 2016); additionally, it might be enhanced by increased endothelial cell activation. Previous studies have revealed the presence of elevated angiogenic factors in the peritoneal fluid, serum, and endometriotic tissues of women with endometriosis as compared to women without endometriosis (Di Carlo et al. 2009). However, a few studies have examined the blood vessels present in the cyst wall tissues of patients with endometrioma. For example, Huang et al. (2012) found that there was a higher microvessel density in ovarian endometriotic lesions than in the control endometrium(Huang et al. 2012). Inan et al. (2003) reported that the mean vascular surface density was significantly higher in the presence of endometriosis than it was in normal ovarian samples. Ceyhan et al. (2008) found that microvessel density was positively correlated with vascular endothelial growth factor (VEGF) and cyclooxygenase-2 expression in endometrioma cyst wall tissues and negatively correlated with cyst diameter. In the present study, we found that women with endometrioma recurrence had significantly higher fractional areas of blood vessels in their ectopic endometrial tissues than did non-recurrence patients. Furthermore, we found a positive correlation between vascularization of the ectopic endometrial tissues and CyPA immunoreactivity.
It is believed that nuclear factor-kappa B (NF-kB) is a critical early regulator of the inflammatory response in endometriotic tissues (Celik et al. 2008). Activation of NF-kB mediates cell proliferation and angiogenesis, which was observed through increases in the vascularized areas of newly-formed microvascular networks and the increased expression of cell proliferation markers in these endometriotic lesions (Wang et al. 2005). CyPA stimulation mediates the rapid activation of $\mathrm{NF}-\mathrm{kB}$ in the nucleus through the degradation of the inhibitory subunit Ikappa B-alpha in the cytoplasm (Li et al. 2008).

In a recent study conducted to investigate the pathway leading to the activation of NF-kB, and the authors showed that MAPKs, ERK1/2, JNK, and p38 were activated by CyPA treatment. However, only the ERK inhibitor PD98059 was able to decrease the activation of NF-kB and attenuate the MMP-9 activity induced by CyPA (Jin et al. 2004). Moreover, previous cancer cell line studies have demonstrated that CyPA secretion is associated with cancer cell proliferation, cell cycles progression, cell invasion, and the migration and inhibition of apoptosis (Choi et al. 2007; Li et al. 2008; Calhoun et al. 2009). Interestingly, an overexpression of CyPA is associated with resistance to chemotherapeutic drugs. Some recent studies have demonstrated that medical treatments with anti-cancer agents such as 5-aza-2-deoxycytidine, celecoxib, 5-fluorouracil, and paclitaxel are related to decreases in CyPA expression within cancer cells (Cecconi et al. 2003; Lou et al. 2006; Wong et al. 2008; Li et al. 2013). However, the knockdown of CyPA or Cyclosporine A and Sanglifehrin treatment, two immunosuppressive drugs that work by binding to CyPA, has been shown to increase the chemotherapeutic effect of cisplatin and paclitaxel in the treatment of glioblastoma multiforme and endometrial cancer (Han et al. 2010; Li et al. 2013).

In conclusion, our present results have shown that women with endometrioma have increased expression of CyPA in both eutopic and ectopic endometrial tissues as compared to women of the control group. Overexpression of CyPA in endometrial tissues, as well as a correlation with recurrence and vascularity, might be associated with a molecular basis for endometriosis pathogenesis. To fully investigate the etiology of and therapeutic approach to endometriosis, the present study suggests further animal model studies to test the inhibition of CyPA and its related pathways as they relate to endometriosis.

\section{Acknowledgments}

The study was supported by Scientific Investigations Foundation of Balikesir University (Project number: BAP.2016/29).

\section{Conflict of Interest}

The authors declare no conflict of interest.

\section{References}

Billich, A., Winkler, G., Aschauer, H., Rot, A. \& Peichl, P. (1997) 
Presence of cyclophilin A in synovial fluids of patients with rheumatoid arthritis. J. Exp. Med., 185, 975-980.

Bischoff, F. \& Simpson, J.L. (2004) Genetics of endometriosis: heritability and candidate genes. Best Pract. Res. Clin. Obstet. Gynaecol., 18, 219-232.

Busacca, M. \& Vignali, M. (2003) Ovarian endometriosis: from pathogenesis to surgical treatment. Curr. Opin. Obstet. Gynecol., 15, 321-326.

Calhoun, C.C., Lu, Y.C., Song, J. \& Chiu, R. (2009) Knockdown endogenous CypA with siRNA in U2OS cells results in disruption of F-actin structure and alters tumor phenotype. Mol. Cell. Biochem., 320, 35-43.

Cecconi, D., Astner, H., Donadelli, M., Palmieri, M., Missiaglia, E., Hamdan, M., Scarpa, A. \& Righetti, P.G. (2003) Proteomic analysis of pancreatic ductal carcinoma cells treated with 5-aza-2'-deoxycytidine. Electrophoresis, 24, 4291-4303.

Celik, O., Hascalik, S., Elter, K., Tagluk, M.E., Gurates, B. \& Aydin, N.E. (2008) Combating endometriosis by blocking proteasome and nuclear factor- $\kappa \mathrm{B}$ pathways. Hum. Reprod., 23, 2458-2465.

Ceyhan, S.T., Onguru, O., Baser, I. \& Gunhan, O. (2008) Expression of cyclooxygenase-2 and vascular endothelial growth factor in ovarian endometriotic cysts and their relationship with angiogenesis. Fertil. Steril., 90, 988-993.

Choi, K.J., Piao, Y.J., Lim, M.J., Kim, J.H., Ha, J., Choe, W. \& Kim, S.S. (2007) Overexpressed cyclophilin A in cancer cells renders resistance to hypoxia- and cisplatin-induced cell death. Cancer Res., 67, 3654-3662.

Defrère, S., González-Ramos, R., Lousse, J.C., Colette, S., Donnez, O., Donnez, J. \& Van Langendonckt, A. (2011) Insights into iron and nuclear factor-kappa B (NF- $\kappa$ B) involvement in chronic inflammatory processes in peritoneal endometriosis. Histol. Histopathol., 26, 1083-1092.

Di Carlo, C., Bonifacio, M., Tommaselli, G.A., Bifulco, G., Guerra, G. \& Nappi, C. (2009) Metalloproteinases, vascular endothelial growth factor, and angiopoietin 1 and 2 in eutopic and ectopic endometrium. Fertil. Steril., 91, 2315-2323.

Exacoustos, C., Zupi, E., Amadio, A., Amoroso, C., Szabolcs, B., Romanini, M.E. \& Arduini, D. (2006) Recurrence of endometriomas after laparoscopic removal: sonographic and clinical follow-up and indication for second surgery. J. Minim. Invasive Gynecol., 13, 281-288.

Grandi, G., Mueller, M.D., Bersinger, N.A., Facchinetti, F. \& McKinnon, B.D. (2017) The association between progestins, nuclear receptors expression and inflammation in endometrial stromal cells from women with endometriosis. Gynecol. Endocrinol., 33, 712-715.

Han, X., Yoon, S.H., Ding, Y., Choi, T.G., Choi, W.J., Kim, Y.H., Kim, Y.J., Huh, Y.B., Ha, J. \& Kim, S.S. (2010) Cyclosporin $\mathrm{A}$ and sanglifehrin A enhance chemotherapeutic effect of cisplatin in C6 glioma cells. Oncol. Rep., 23, 1053-1062.

Ho, H.N., Wu, M.Y. \& Yang, Y.S. (1997) Peritoneal cellular immunity and endometriosis. Am. J. Reprod. Immunol., 38, 400-412.

Huang, X., Chen, L., Fu, G., Xu, H. \& Zhang, X. (2012) Decreased expression of pigment epithelium-derived factor and increased microvascular density in ovarian endometriotic lesions in women with endometriosis. Eur. J. Obstet. Gynecol. Reprod. Biol., 165, 104-109.

Inan, S., Kuscu, N.K., Vatansever, S., Ozbilgin, K., Koyuncu, F. \& Sayhan, S. (2003) Increased vascular surface density in ovarian endometriosis. Gynecol. Endocrinol., 17, 143-150.

Jin, Z.G., Lungu, A.O., Xie, L., Wang, M., Wong, C. \& Berk, B.C. (2004) Cyclophilin A is a proinflammatory cytokine that activates endothelial cells. Arterioscler. Thromb. Vasc. Biol., 24, 1186-1191.

Laschke, M.W., Giebels, C. \& Menger, M.D. (2011) Vasculogenesis: a new piece of the endometriosis puzzle. Hum. Reprod.
Update, 17, 628-636.

Li, Y., Adur, M.K., Kannan, A., Davila, J., Zhao, Y., Nowak, R.A., Bagchi, M.K., Bagchi, I.C. \& Li, Q. (2016) Progesterone Alleviates Endometriosis via Inhibition of Uterine Cell Proliferation, Inflammation and Angiogenesis in an Immunocompetent Mouse Model. PLoS One, 11, e0165347.

Li, Z., Min, W. \& Gou, J. (2013) Knockdown of cyclophilin A reverses paclitaxel resistance in human endometrial cancer cells via suppression of MAPK kinase pathways. Cancer Chemother. Pharmacol., 72, 1001-1011.

Li, Z., Zhao, X., Bai, S., Wang, Z., Chen, L., Wei, Y. \& Huang, C. (2008) Proteomics identification of cyclophilin a as a potential prognostic factor and therapeutic target in endometrial carcinoma. Mol. Cell. Proteomics, 7, 1810-1823.

Lou, J., Fatima, N., Xiao, Z., Stauffer, S., Smythers, G., Greenwald, P. \& Ali, I.U. (2006) Proteomic profiling identifies cyclooxygenase-2-independent global proteomic changes by celecoxib in colorectal cancer cells. Cancer Epidemiol. Biomarkers Prev., 15, 1598-1606.

Matsuzaki, S. \& Schubert, B. (2010) Oxidative stress status in normal ovarian cortex surrounding ovarian endometriosis. Fertil. Steril., 93, 2431-2432.

Missmer, S.A., Hankinson, S.E., Spiegelman, D., Barbieri, R.L., Malspeis, S., Willett, W.C. \& Hunter, D.J. (2004) Reproductive history and endometriosis among premenopausal women. Obstet. Gynecol., 104, 965-974.

Nigro, P., Satoh, K., O’Dell, M.R., Soe, N.N., Cui, Z., Mohan, A., Abe, J., Alexis, J.D., Sparks, J.D. \& Berk, B.C. (2011) Cyclophilin A is an inflammatory mediator that promotes atherosclerosis in apolipoprotein E-deficient mice. J. Exp. Med., 208, 53-66.

Ramachandran, S., Venugopal, A., Kutty, V. R., A, V., G, D., Chitrasree, V., Mullassari, A., Pratapchandran, N.S., Santosh, K.R., Pillai, M.R. \& Kartha, C.C. (2014) Plasma level of cyclophilin A is increased in patients with type 2 diabetes mellitus and suggests presence of vascular disease. Cardiovasc. Diabetol., 13, 38.

Reuter, S., Gupta, S.C., Chaturvedi, M.M. \& Aggarwal, B.B. (2010) Oxidative stress, inflammation, and cancer: how are they linked? Free Radic. Biol. Med., 49, 1603-1616.

Sanchez, A.M., Viganò, P., Somigliana, E., Panina-Bordignon, P., Vercellini, P. \& Candiani, M. (2014) The distinguishing cellular and molecular features of the endometriotic ovarian cyst: from pathophysiology to the potential endometriomamediated damage to the ovary. Hum. Reprod. Update, 20, 217-230.

Satoh, K., Fukumoto, Y., Sugimura, K., Miura, Y., Aoki, T., Nochioka, K., Tatebe, S., Miyamichi-Yamamoto, S., Shimizu, T., Osaki, S., Takagi, Y., Tsuburaya, R., Ito, Y., Matsumoto, Y., Nakayama, M., et al. (2013) Plasma cyclophilin A is a novel biomarker for coronary artery disease. Circ. J., 77, 447-455.

Satoh, K., Nigro, P., Zeidan, A., Soe, N.N., Jaffré, F., Oikawa, M., O’Dell, M.R., Cui, Z., Menon, P., Lu, Y., Mohan, A., Yan, C., Blaxall, B.C. \& Berk, B.C. (2011) Cyclophilin A promotes cardiac hypertrophy in apolipoprotein E-deficient mice. Arterioscler. Thromb. Vasc. Biol., 31, 1116-1123.

Seizer, P., Ochmann, C., Schönberger, T., Zach, S., Rose, M., Borst, O., Klingel, K., Kandolf, R., MacDonald, H.R., Nowak, R.A., Engelhardt, S., Lang, F., Gawaz, M. \& May, A.E. (2011) Disrupting the EMMPRIN-Cyclophilin A interaction reduces infarct size and preserves systolic function after myocardial ischemia and reperfusion. Arterioscler. Thromb. Vasc. Biol., 31, 1377-1386.

Singh, S.S. \& Suen, M.W.H. (2017) Surgery for endometriosis: beyond medical therapies. Fertil. Steril., 107, 549-554.

Soliman, A.M., Coyne, K.S., Zaiser, E., Castelli-Haley, J. \& Fuldeore, M.J. (2017) The burden of endometriosis symptoms on health-related quality of life in women in the United States: a cross-sectional study. J. Psychosom. Obstet. Gynaecol., 38, 
238-248.

Stemmy, E.J., Balsley, M.A., Jurjus, R.A., Damsker, J.M., Bukrinsky, M.I. \& Constant, S.L. (2011) Blocking cyclophilins in the chronic phase of asthma reduces the persistence of leukocytes and disease reactivation. Am. J. Respir. Cell Mol. Biol., 45, 991-998.

Tian-tian, Z., Jun-feng, Z. \& Heng, G. (2013) Functions of cyclophilin A in atherosclerosis. Exp. Clin. Cardiol., 18, e118e124.

Vercellini, P., Fedele, L., Aimi, G., De Giorgi, O., Consonni, D. \& Crosignani, P.G. (2006) Reproductive performance, pain recurrence and disease relapse after conservative surgical treatment for endometriosis: the predictive value of the current classification system. Hum. Reprod., 21, 2679-2685.

Wang, F., He, Y., Peng, D. \& Liu, M. (2005) Expressions of nuclear factor-kappaB and intercellular adhesion molecule-1 in endometriosis. Di Yi Jun Yi Da Xue Xue Bao., 25, 703-705(in Chinese).

Wang, L., Wang, C.H., Jia, J.F., Ma, X.K., Li, Y., Zhu, H.T., Tang, H., Chen, Z.N. \& Zhu, P. (2010) Contribution of cyclophilin A to the regulation of inflammatory processes in rheumatoid arthritis. J. Clin. Immunol., 30, 24-33.

Wong, C.S., Wong, V.W., Chan, C.M., Ma, B.B., Hui, E.P., Wong, M.C., Lam, M.Y., Au, T.C., Chan, W.H., Cheuk, W. \& Chan,
A.T. (2008) Identification of 5-fluorouracil response proteins in colorectal carcinoma cell line SW480 by two-dimensional electrophoresis and MALDI-TOF mass spectrometry. Oncol. Rep., 20, 89-98.

Wu, W.S. (2006) The signaling mechanism of ROS in tumor progression. Cancer Metastasis Rev., 25, 695-705.

Yamaguchi, K., Mandai, M., Toyokuni, S., Hamanishi, J., Higuchi, T., Takakura, K. \& Fujii, S. (2008) Contents of endometriotic cysts, especially the high concentration of free iron, are a possible cause of carcinogenesis in the cysts through the ironinduced persistent oxidative stress. Clin. Cancer Res., 14, 32-40.

Yamamoto, A., Johnstone, E.B., Bloom, M.S., Huddleston, H.G. \& Fujimoto, V.Y. (2017) A higher prevalence of endometriosis among Asian women does not contribute to poorer IVF outcomes. J. Assist. Reprod. Genet., 34, 765-774.

Yang, H., Chen, J., Yang, J., Qiao, S., Zhao, S. \& Yu, L. (2007) Cyclophilin A is upregulated in small cell lung cancer and activates ERK1/2 signal. Biochem. Biophys. Res. Commun., 361, 763-767.

Yang, Y., Lu, N., Zhou, J., Chen, Z.N. \& Zhu, P. (2008) Cyclophilin A up-regulates MMP-9 expression and adhesion of monocytes/macrophages via CD147 signalling pathway in rheumatoid arthritis. Rheumatology (Oxford)., 47, 1299-1310. 